\title{
Manejo perioperatorio de feocromocitoma en pediatría: reporte de caso
}

\author{
Odicino MC. ${ }^{1,2}$. \\ 1 Hospital de Niños de la Santísima Trinidad, Córdoba, Argentina. \\ 2 Córdoba.
}

Introducción: Los feocromocitomas son tumores que pueden secretar grandes cantidades de catecolaminas. Para su manejo y preparación perioperatoria hay una gran cantidad de información publicada sobre fármacos que pueden utilizarse pero no tan extensa en niños

Caso clínico: Niño de 6 años de edad ingresa en el año 2017 a cirugía para resección de tumor suprarrenal. Desde el inicio de su cirugía el niño mantiene valores de TA por encima del rango esperado y para el plano anestésico otorgado. Durante la manipulación del tumor eleva aún más la tensión y desencadena taquiarritmia que requiere la utilización de Esmolol. Se realiza adrenalectomía y pasa a UTI. Su posquirúrgico fue tórpido, con acidosis metabólica sostenida y de difícil manejo. Mejora y se le otorga el alta. Anatomía patológica de la pieza confirma que era un feocromocitoma. Un año después vuelve a control. Se realiza TAC de abdomen donde se detecta masa en suprarrenal contralateral y el examen físico revela cifras de TA elevada para su edad (160/100). Medición de vainilmandelico y derivados elevados. Ecocardiograma informa hipertrofia ventricular concéntrica con función sistólica conservada. Se inicia tratamiento alfabloqueante (doxazocina) para preparación quirúrgica. Luego, se inicia tratamiento con propanolol. Se consigue estabilizar cifras de tensión arterial 11 días después de su admisión. Ingresa a quirófano premedicado con midazolam $(0,1 \mathrm{mg} / \mathrm{kg})$ y carga de hidrocortisona por su adrenalectomía previa. La Inducción se realizó con sevofluorano al 2-4\% remifentanilo $0,5 \mu \mathrm{gr} / \mathrm{kg} / \mathrm{min}$ y vecuronio $0,1 \mathrm{mg} / \mathrm{kg}$. Ventilación e intubación sin dificultad con TET acorde a edad. Mantenimiento con sevoflourano más remifentanilo. El intraoperatorio transcurre dentro de lo esperado, durante la manipulación del tumor se inicia NTG $(0,10,15 \mathrm{~g})$ luego, durante el clampeo vascular se inició infusión con NAD (0,1 -0,2 g) más expansión con coloides a $10 \mathrm{ml} / \mathrm{kg}$. En todo momento el niño tuvo respuesta favorable a las intervenciones del anestesiólogo. Se decide extubación en quirófano y pasa a UTI con infusión de NAD a 0,05 g. Postquirúrgico bueno. Se retira la infusión de vasopresores a las pocas horas. Recibe alta 5 días después.

Discusión: En la búsqueda de información publicada sobre el tratamiento perioperatorio en niños nos encontramos con que la experiencia es escasa. Algunos autores postulan el uso de alfa bloqueantes de acción corta como prazocin o doxazocina.

Conclusiones: La aparición del segundo tumor en el mismo niño permitió ver la diferencia de comportamiento y evolución tanto en el intraoperatorio como en el posquirúrgico.

https://doi.org/10.25237/congresoclasa2019.62 